\title{
Influence of age on Doppler echocardiographic indices of left ventricular diastolic function
}

Sir,

We read with interest Spirito and Maron's article (1988;59:672-9). Their conclusions about the effect of aging on diastolic left ventricular filling accord with ours. ${ }^{1}$ We showed that atrial filling fractions increased significantly with age in normal subjects from $12 \%$ to $46 \%$, and we concluded that "agecorrected nomograms are mandatory in assessing atrial filling fraction in individual patients". We also found, as did others, ${ }^{2}$ that mitral regurgitation can augment early diastolic filling and alter the left ventricular filling pattern. Even slight mitral regurgitation can influence the inflow pattern and can lead to apparent normalisation of early diastolic filling in patients with disturbed diastolic function. This implies that when Doppler echocardiography is used to study left ventricular filling, mitral regurgitation should be taken into account, especially, as it can be clinically silent.

\author{
Edward G Abinader, \\ Dawod S Sharif, \\ Heart Institute and Coronary Care Unit, \\ Haifa Medical Centre, \\ Faculty of Medicine, \\ Technion, Haifa, Israel.
}

\section{References}

1 Kuo LC, Quinones MA, Rokey R, Sartori M, Abinader EG, Zoghbi WA. Quantification of atrial contribution to left ventricular filling by pulsed Doppler echocardiography and the effect of age in normal and diseased hearts. Am J Cardiol 1987;59:1174-8.

2 Shaikh AM, Lavine SJ. Effect of mitral regurgitation on diastolic filling with left ventricular hypertrophy. $\mathrm{Am}$ $J$ Cardiol 1988;61:590-4. 